\title{
PENTINGNYA RUANG IBU DAN ANAK SEBAGAI FASILITAS PENDUKUNG KEGIATAN MENYUSUI DI AREA PUBLIK
}

\author{
Ulli Aulia Ruki \\ Jurusan Desain Interior, Fakultas Komunikasi Multimedia, Bina Nusantara University \\ Jl. K.H. Syahdan No. 9, Palmerah, Jakarta Barat 11480 \\ ulliaulia@gmail.com
}

\begin{abstract}
A variety of interior now days have become diversly demand following on the customer needs as the visitor in the public space. Nowadays, department store start narrowing down its service facilities based on visitor needs such as children indoor playground, pray room, and nursery room. Nowdays mothers are aware of the importance to breastfeed exclusively their baby in their first six months; Breastfeeding is the new lifestyle. Nevertheless, there are only a few rooms that fully supported breastfeeding activity in public area. This journal will give the idea about a proper interior should be applied in the nursery room and the advantages of being supported to the breastfeeding activity for management mall or company who are providing the room as their services. Data are given by analysis and comparing the proper or deficient interior on several nursery rooms. In conclude, facilitating an appropriate, comfort and hygienist rooms for mother and baby are one of the approach to be acknowledged as the excellent services by the customer.
\end{abstract}

Keywords: mother and baby room, breastfeeding facility, public space

\begin{abstract}
ABSTRAK
Fasilitas ragam ruang di ruang publik saat ini semakin berkembang, ini dapat terjadi dikarenakan adanya aktivitas yang terus berkembang menjadi gaya hidup masa kini bagi masyarakatnya. Pusat perbelanjaan saat ini sudah mulai menyediakan fasilitas seperti area khusus bermain anak, ruang beribadah dan juga ruang khusus menyusui sebagai bagian dari servis yang disediakan untuk pengunjungnya. Sekarang ini, semakin banyak ibu-ibu yang menyadari arti pentingnya menyusui bayi nya selama 6 bulan pertama dalam kehidupannya secara ekslusif: Breastfeeding is the new life style. Namun keberadaan ruangan ibu dan anak ini hanya beberapa saja yang menyediakan secara lengkap kebutuhan dari kegiatan menyusui di area publik. Di dalam jurnal ini akan memberikan beberapa ide tentang bagaimana interior yang sepatutnya diterapkan pada ruangan menyusui. Data yang diberikan melewati tahapan analisis terhadap interior yang baik dan tidak nyaman pada beberapa ruangan ibu dan anak. Simpulannya adalah dengan memberikan fasilitas yang nyaman, baik dan higienis untuk para ibu serta bayinya adalah salah satu cara untuk dapat dikenal sebagai area public dengan servis yang sangat baik bagi pelanggannya
\end{abstract}

Kata kunci: ruang ibu dan anak, fasilitas menyusui, area public 


\section{PENDAHULUAN}

WHO telah mengumumkan bahwa kegiatan menyusui bayi baru lahir secara ekslusive selama 6 bulan adalah penting, hal ini dikarenakan ASI adalah nutrisi pertama yang mengandung sistem imun terbaik bagi bayi yang baru lahir dan dilakukan sampai dengan bayi berumur dua tahun. Organisasi ini sangat memberi dukungan kegiatan ibu menyusui dan masyarakat luas untuk dapat memberikan fasilitas tersebut. Oleh karena itu penelitian ini akan mencoba untuk menyusun tentang bagaimana dukungan dan keberadaan ruang menyusui (nursery room) yang baik pada area publik seperti pusat perbelanjaan, rumah sakit dan juga gedung perkantoran.

Area Mengurus bayi di area publik semakin diperlukan dan semakin penting karena banyak dari ibu yang harus kembali beraktifitas normal di luar rumah setelah berakhirnya masa cuti 3 bulan, namun ingin tetap menyusui bayinya secara ekslusive selama 6 bulan. kegiatan ibu antara lain adalah kembali bekerja dikantornya, mengantarkan bayinya ke rumah sakit untuk melakukan imunisasi setiap tiga bulan sekali dan berbelanja keperluan rumah tangga di mall ataupun pasar swalayan dan kegiatan lainnya di luar rumah.

\section{PEMBAHASAN}

\section{Nursery Room (Ruang Ibu dan Anak)}

Nursery room atau tempat mengurus bayi adalah suatu ruangan yang disediakan peruntukkannya sebagai area khusus ibu yang memerlukan ruangan dengan tingkatan yang lebih privasi untuk melakukan kegiatan mengurus bayi serta menyusui anak bayi dibawah tiga tahun. Di dalam ruangan ibu dan anak kegiatan utamanya tidak lain adalah ibu yang menyusui bayinya, orang tua yang mengganti popok bayi dan balitanya serta kegiatan yang ada di toilet anak-anak. Lama kegiatan tersebut biasanya antara 15-30 menit, tergantung dengan seberapa cepat bayi menyusu dan ibu menggantikan popok.

Banyak orang tua yang juga sedang melatih anak balitanya dalam program toilet training, sehingga balita masih dibantu untuk menggunakan ruang toilet tersebut. Namun hal ini dapat menjadi rancu dikarenakan ada beberapa orang tua yang juga membawa masuk bapak atau suami ke dalam ruang untuk membantu si ibu. Oleh sebab itu alangkah baiknya bila dimulai dengan mengkategorikan aktifitas berdasarkan privasi dan higinietas untuk sebuah perencanaan interior ruang menyusui. Berikut adalah contoh dari ruang menyusui dengan kelengkapan berapa furniture yang diperlukan untuk fasilitas menyusui seperti, meja ganti diapers, tempat duduk menyusui, wastafel untuk cuci tangan, WC anak balita, cermin, tempat sampah dan tempat tisu serta pengering tangan.

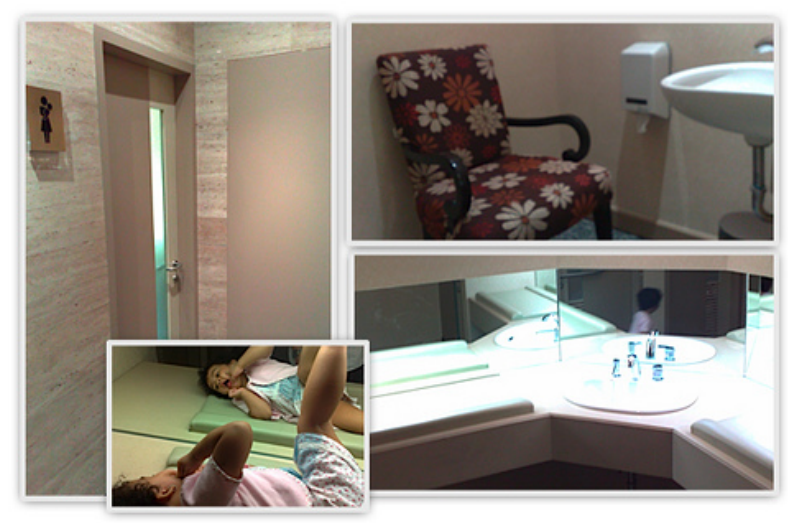

Gambar 1 Perlengkapan Dasar yang Dibutuhkan di Ruang Menyusui 


\section{Ruang Menyusui di Pusat Perbelanjaan}

Bila sebelumnnya menyusui dapat dikatakan sebuah kegiatan yang menyulitkan karena tidak tersediannya ruangan khusus, kali ini nursery room sudah lebih mudah ditemukan di pusat-pusat perbelanjaan, hal ini memberikan dampak positif bagi management sebagai pernyataan dukungan untuk ibu dalam aktifitas menyusui bayinya. Dengan demikian tingkat kepuasan pengunjung yang datang ke mall tersebut dapat meningkat, selain itu mall tersebut dapat menjadi mall pilihan karena fasilitas servisnya yang lengkap untuk ibu yang akan membawa bayinya jalan-jalan. Di bawah ini adalah salah satu contoh dari ruangan menyusui yang disediakan oleh management mall.

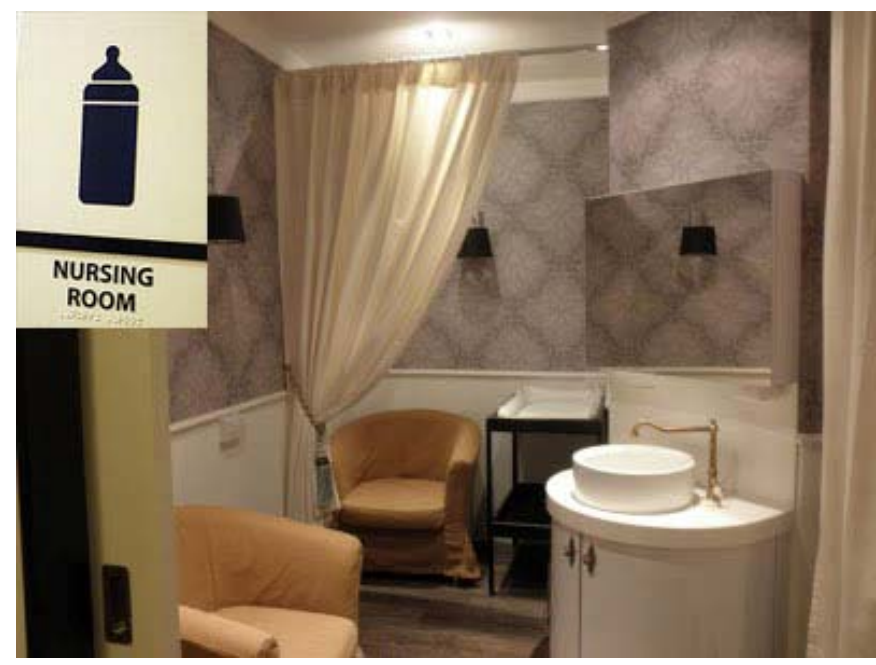

Gambar 2 Ruang menyusui di forum galleria mall Singapura

Ada beberapa hal yang perlu dipertimbangkan dalam merencanakan sebuah nursing room di pusat perbelanjaan antara lain adalah area yang cukup untuk bilik-bilik meyusui, area untuk mengganti popok bayi, WC khusus balita (toilet training) dan area untuk menyimpan kereta dorong. Pengguna dari ruang menyusui sebaiknya dibatasi dan memperhatikan tingkatan usia dari pengguna fasilitas tersebut. Pengguna fasilitas menyusui rata-rata adalah ibu-ibu yang mempunyai balita atau dapat dikategorikan berdasarkan usia balita 0-6 bulan, 6-12 bulan, 12-24 bulan dan untuk pengguna fasilitas toilet training adalah untuk anak berumur 2 tahun - 5 tahun yang masih memerlukan bantuan pada saat melakukan aktifitas dikamar mandi. Berikut adalah diagaram bubble dari aktifitas di ruang menyusui pusat perbelanjaan.

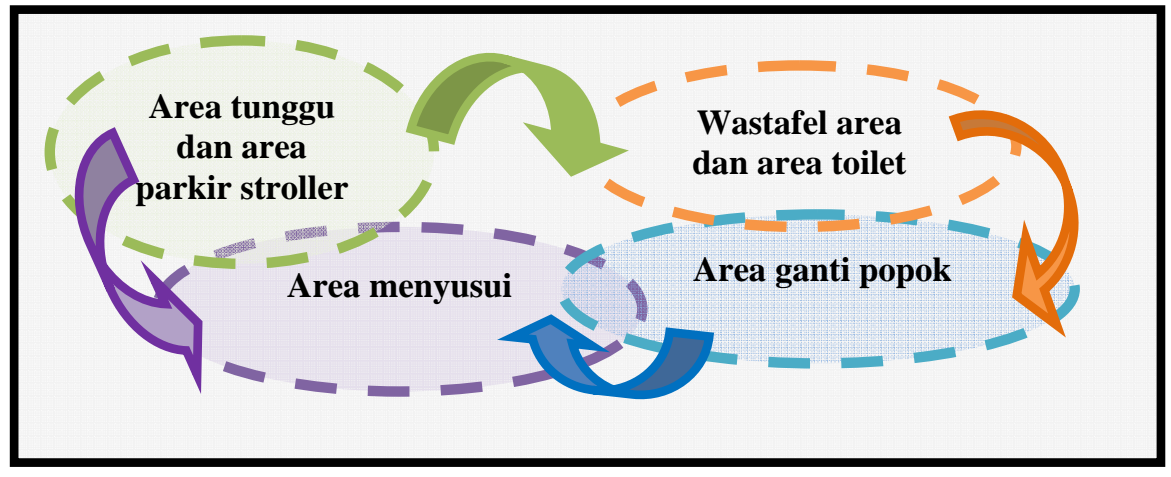

Gambar 3 Akvifitas pada ruang menyusui di pusat perbelanjaan 


\section{Ruang Menyusui Anak di Kantor}

Wanita Indonesia yang bekerja hanya memiliki jatah cuti selama 3 bulan setelah melahirkan bayinya dan dari penelitian yang dilakukan oleh asosiasi ibu menyusui Indonesia (AIMI) banyak pendapat wanita yang bekerja dengan sangat mudah memberhentikan kegiatan menyusuinya setelah mereka kembali bekerja. Hal ini dikarenakan tidak adanya dari kebijakan kantor yang memberikan waktu dan tempat untuk para ibu menyusui ini melakukan kegiatan memerah susu asinya dan tempat untuk penyimpanan asi perahan. Berikut adalah fasilitas menyusui yang ada di perkantoran.

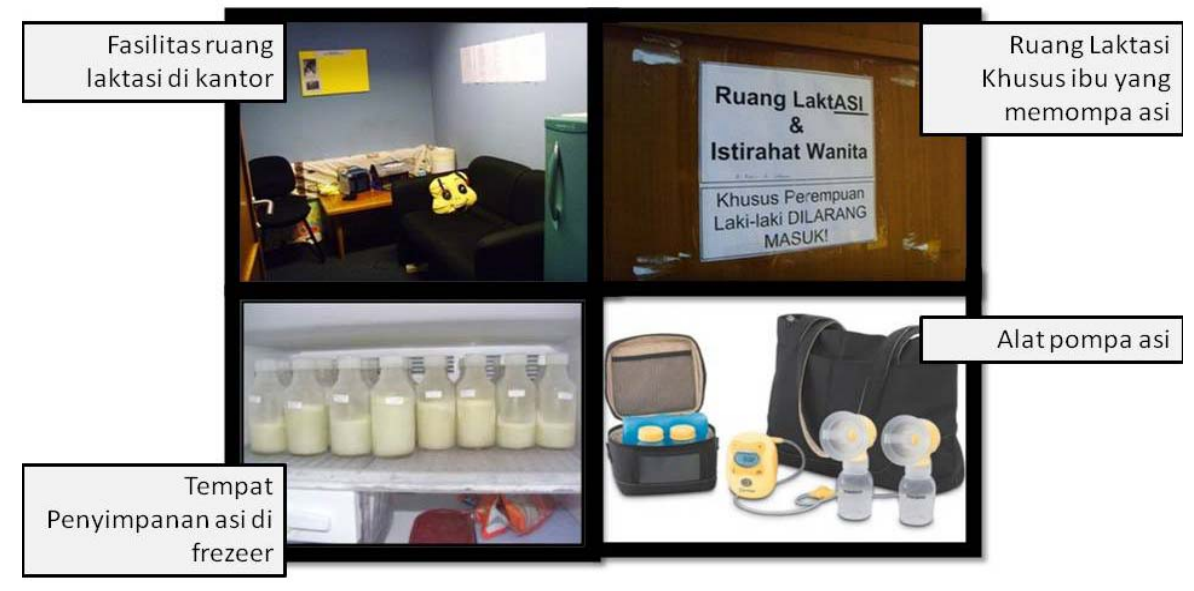

Gambar 4 Ruang laktasi ataupun ruangan menyusui di kantor

Pada dasarnya ruang menyusui di perkantoran berbeda dengan ruang menyusui di pusat perbelanjaan. Perkantoran bukanlah tempat yang tepat membawa bayi, namun alangkah lebih baik menurut sentra laktasi Indonesia (selasinet) bila ada perusahaan yang mengikuti gerakan "saying bayi" dapat menyediakan fasilitas penitipan anak dan ruang memerah dilengkapi dengan kulkas khusus untuk menyimpan asi perahan sementara menunggu jam kantor selesai. Waktu yang diperlukan memerah cukup minimal 1 jam per hari (3-4 kali perhari cukup dengan 15menit persesi perah). Berikut adalah gambar aktivitas pada ruang menyusui di kantor:

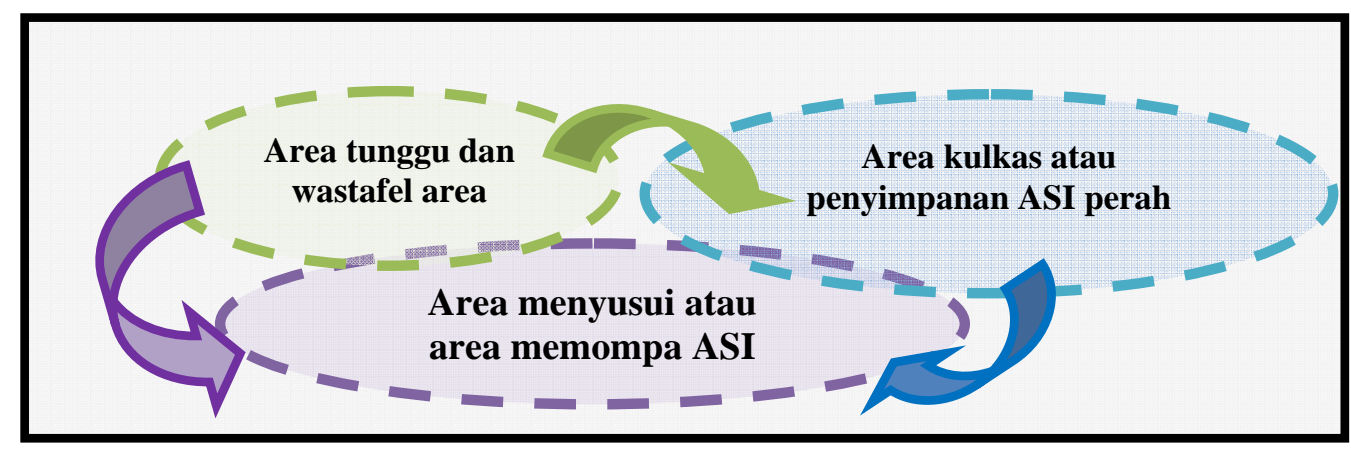

Gambar 5 Aktivitas pada ruang menyusui di kantor

Beberapa keuntungan bagi perusahaan yang mengikuti gerakan perusahaan saying ibu yang telah dicanangkan oleh sentra laktasi Indonesia dengan mengikuti program yang dicanangkan UNICEF, yaitu (1) mengurangai biaya kesehatan ibu dan bayi, dengan mendukung ibu menyusui, ibu 
dapat mengurangi biaya kesehatan yang dikeluakan perusahaan; (2) mengurangi angka absen, dengan bayi yang sehat maka angka ibu bekerja yang absen karena alasan tidak bisa bekerja mengurus anaknya yang sakit dapat dikurangi; (3) meningkatkan produktivitas karyawan, menyusui membuat ibu lebih sehat, karena ibu tersebut memeperhatikan gaya hidup dan pola makanan. Selain itu beberapa ibu mulai bekerja dengan lebih disiplin karena mempunyai jadwal untuk memompa asi perah untuk bayinya; (4) mengurangi turnover staf, karyawati akan sehat dan bahagia bekerja pada perusahaan yang mendukung keputusannya tetap bekerja dengan tidak menelantarkan kebutuhan bayinya. Sehingga perusaan tidak perlu kehilangan karyawatinya yang sudah menjadi tenaga ahli di kantornya; (5) meningkatkan reputasi perusahaan, perusahaan akan dikenal dengan image yang positif karena memperhatikan kesehatan karyawannya; (6) mengurangi stress pekerja wanita.

Dengan adanya perusahaan yang mencangankan gerakan sayang ibu, maka kegiatan ibu dapat tetap konsentarsi bekerja tidak terganggu oleh kekhawatiran anak bayi ASI yang lebih sehat serta bayi yang dititipkan di TPA (tempat penitipan anak) yang ada dikantornya; (7) menambah requirement incentive bagi pekerja wanita muda yang potensial. Perusahaan akan menarik tenaga muda yang berbakat untuk melamar pekerjaan yang mempunyai kebijakan meyusui dan juga TPA di kantornya.

\section{Ruang Menyusui di Rumah Sakit}

Lain dengan halnya ruang menyusi di area rumah sakit, penggunanya dapat dikategorikan dengan kondisi kesehatannya pada saat berada di rumah sakit. Hal ini dilakukan untuk menjaga higienitas dan pencegahan dari menularnya suatu penyakit yang mungkin sedang diderita si pasien. Untuk lebih jelasnya dapat dilihat dari Gambar 6 berikut

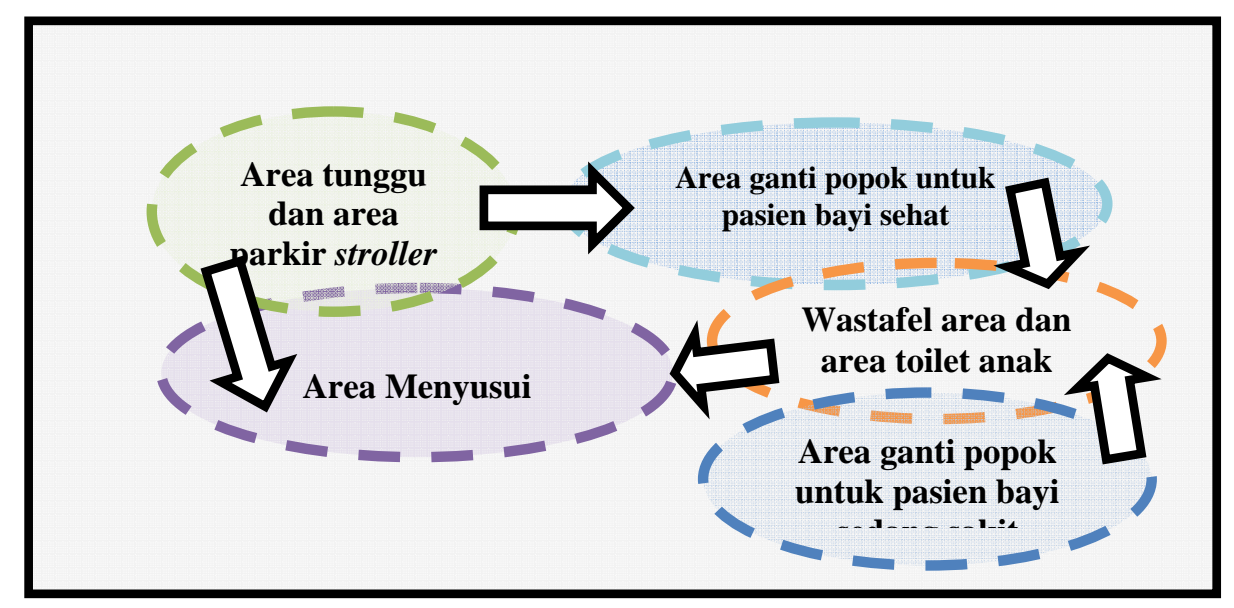

Gambar 6 Aktivitas ruang menyusui di area rumah sakit

\section{Element Interior Ruang Menyusui}

Pada saat merencanakan sebuah interior yang digunakan oleh anak, sebaiknya designer memahami terlebih dahulu tentang psikologis balita melalu kriteria tahapan perkembangan balita. Tahapan perkembangan anak, yaitu: (1) usia 0-3 bulan bayi mulai merasakan refleks dari mulut, kulit dan juga cahaya yang terang; (2) bayi 3-6 bulan mulai membedakan suara dan tertarik pada benda berwarna, menyentuh tekstur benda yang berbeda, menoleh pada suara, bayi juga sudah mulai mencoba yang membalikan badan; (3) bayi 6-9 bulan sudah mulai tertarik dengan jari tangan dan kakinya, belajar duduk, memperhatikan gerak gerik orang dan tertarik pada bayangan dalam cermin, serta mengoceh; (4) usia bayi 9-12 bulan mulai merayap, berdiri tanpa bantuan, bermain dengan kedua tangan dan kakinya, melakukan tugas sederhana seperti melempar, tepuk tangan, memindahkan barang pada tangan kanan dan kiri, mengayunkan benda yang dipegangnya dan mengayunkan kaki. 
Dengan pertimbangan pengenalan proses dasar pengembangan dari anak tersebut, designer dapat lebih memperhatikan aspek teknis dan non teknis pada saat mendesign ruangan ibu dan anak tersebut. Aspek teknis yang dimaksud adalah memperhatikan keamanan dan kemungkinan jenis bahaya seperti jatuh karena lantai licin, bahaya dari sengatan listrik, kebakaran, pemilihan material kaca, sisi ergonomis ukuran furnitur, pemilihan warna yang tidak nyaman, material yang beracun dan juga pencurian. Aspek non teknis disini adalah dengan memperhatikan pola atau kebiasaan si pemakai dalam menggunakan fasilitas ruang tersebut sepert contohnya kebiasaan baby sitter atau suami ikut menunggu di dalam, kebiasaan ibu dalam membersihkan kotoran bayi di toilet dalam posisi berdiri atau duduk, kebiasaan membawa masuk stroller ke area ganti popok, kebiasaan pengguna untuk membuang sampah, kebiasaan pengguna dalam mencuci tangan sebelum dan setelah menyusui. Sehingga diperlukannya sarana penunjang seperti area parkir stroller, ruang tunggu, bilik menyusui, toilet khusus dengan ukuran ergonomic anak-anak dan juga bentuk dan posisi penempatan tempat sampah yang dekat dengan tempat mengganti popok.

\section{Dinding}

Menggunakan cat yang antitoksin (non-toxic paint) adalah salah satu yang sangat direkomendasikan untuk penyelesaian bidang di dinding ruangan bayi dan anak, ruangan ibu hamil dan menyusui ataupun rumah sakit. Kesehatan bayi masih sangat rentan dan lebih sensitif pada bahanbahan kimia yang ada di sekitarnya, oleh karena itu sebaiknya pemakaian bahan kimia sebaiknya dibatasi dari kandungan produk makanan, produk sabun ataupun produk furniturenya.

Non-toxic paint adalah produk yang tidak $100 \%$ terbebas bahan kimia terutama pada campuran cat, namun non-toxic disini adalah bahan cat yang presentasenya masih diambang batas toleransi yang dapat dikendalikan efek sampingnya. Ada dua jenis cat yang berbahan dasar natural, yaitu casein-tempera paints dan eggtempera yaitu teknik cat yang dipakai pada jaman eyptian dengan bahan dasar susu dan telur. Namun kedua cat tersebut masih sulit ditemukan. Beberapa keuntungan bila menggunakan bahan cat yang bebas bahan beracun adalah: (1) mengurangi alergi terutama bagi kesehatan yang sensitif terhadap kandungan bahan kimia pada cat biasa; (2) mengurangi perusakan lapisan ozon dengan mengurangi pencemaran yang ada di udara pada saat mengecat; (3) cat dengan bahan dasar air sangatlah mudah dibersikan dengan air sabun dan air hangat; (4) membersihkannya lebih mudah karena tidak memerlukan cairan khusus; (5) pada saat mengaplikasikan cat tersebut tidak membuat ruangan beraroma gas dan bau aromanya dapat segera hilang.

\section{Ceiling}

Desain dari ceiling yang terbuka sebaiknya dikurangi penggunaannya agar kontrol terhadap debu ataupun pemeliharaannya dapat dikerjakan dengan mudah. Selain itu untuk expose ceiling memberikan kesan suram pada bagian yang gelap karena tidak terkena cahaya.

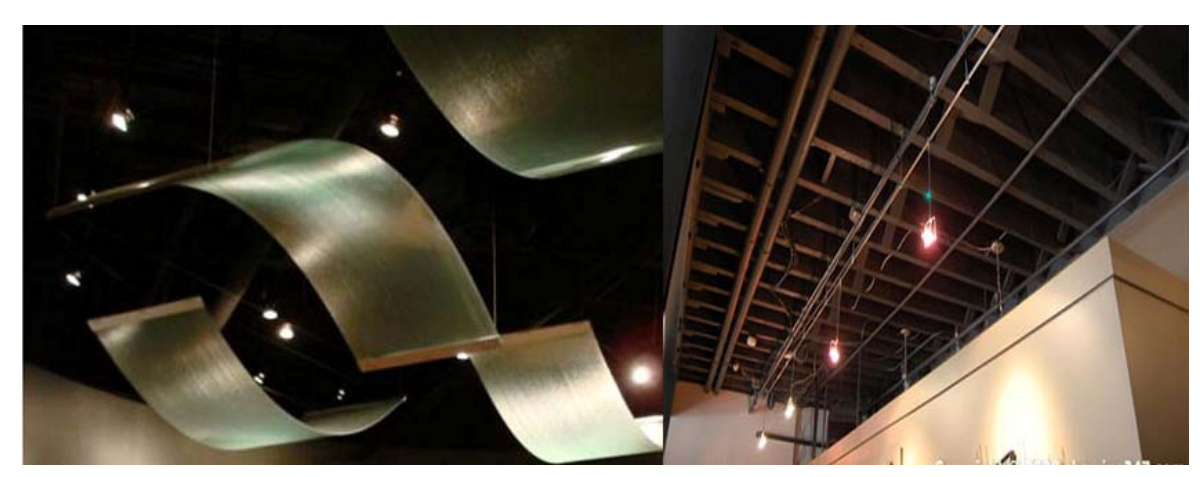

Gambar 7 Bentuk Ceiling Terbuka Perlu Dihindari untuk Nursery Room 
Untuk lebih menarik, dapat menggunakan ceiling yang dilukis ataupun penambahan cahaya lampu yang dapat menarik perhatian bayi dalam posisi terlentang untuk diganti popoknya oleh sang ibu. Penggunaan material gypsum dan rangka besi atau kayu dapat digunakan karena bahan tersebut mudah didapat dan dibentuk serta lebih mudah dalam pemeliharaannya. Berikut adalah contoh dari ceiling yang dilukis dari bahan gypsum.

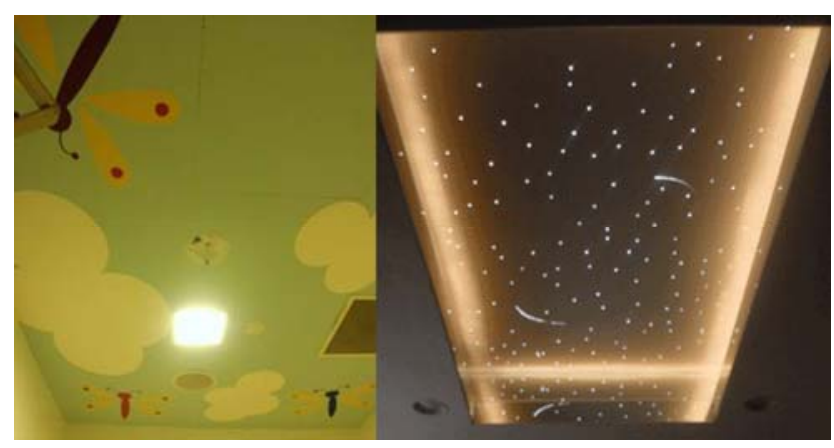

Gambar 8 Alternatif Desain Ceiling untuk Nursery Room

\section{Lantai}

Material lantai yang digunakan sebaiknya tidak licin dan mudah dibersihkan. Material dengan campuran bahan vinil sangat mudah dibersihkan dan juga tidak menampung debu seperti karpet, selain itu pemilihan vinil sangatlah baik meredam bising pada ruangan dengan aktivitas yang intensitas dan lalu lintasnnya alurnya tinggi seperti teriakan anak kecil, dan tangisan bayi. Berikut adalah contoh gambar lantai dengan bahan vinil.

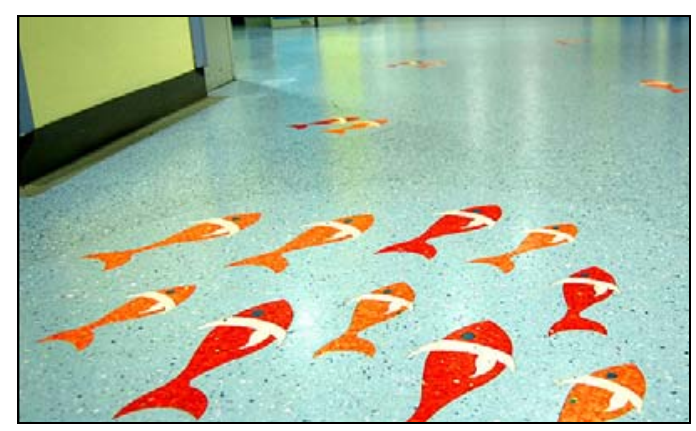

Gambar 9 Material Lantai Berbahan Dasar Vinil

Lantai vinil sekarang ini sudah makin beragam, banyak pilihan warna dan juga motif sehingga tidak perlu lagi khawatir cara untuk mendesainnya. Alternatif penggunaan material lantai seperti keramik dan granit marmer juga dapat digunakan, namun banyak dari penggunaan dari bahan tersebut sulit membentuk gambar. Lain halnya dengan vinil karena pemasangannya yang mudah, vinil dapat diganti bila mulai jenuh dengan gambar yang lain.

\section{Bentuk dan Material Furnitur}

Untuk penggunaan furnitur lebih baik bila menggunakan lapisan yang bukan berbahan plastic, karena bahan dasar plastik terbuat dari campuran dari bahan kimia yang bisa membahayakan kesehatan serta pinggiran yang tajam pada furniture dapat melukai si anak. 


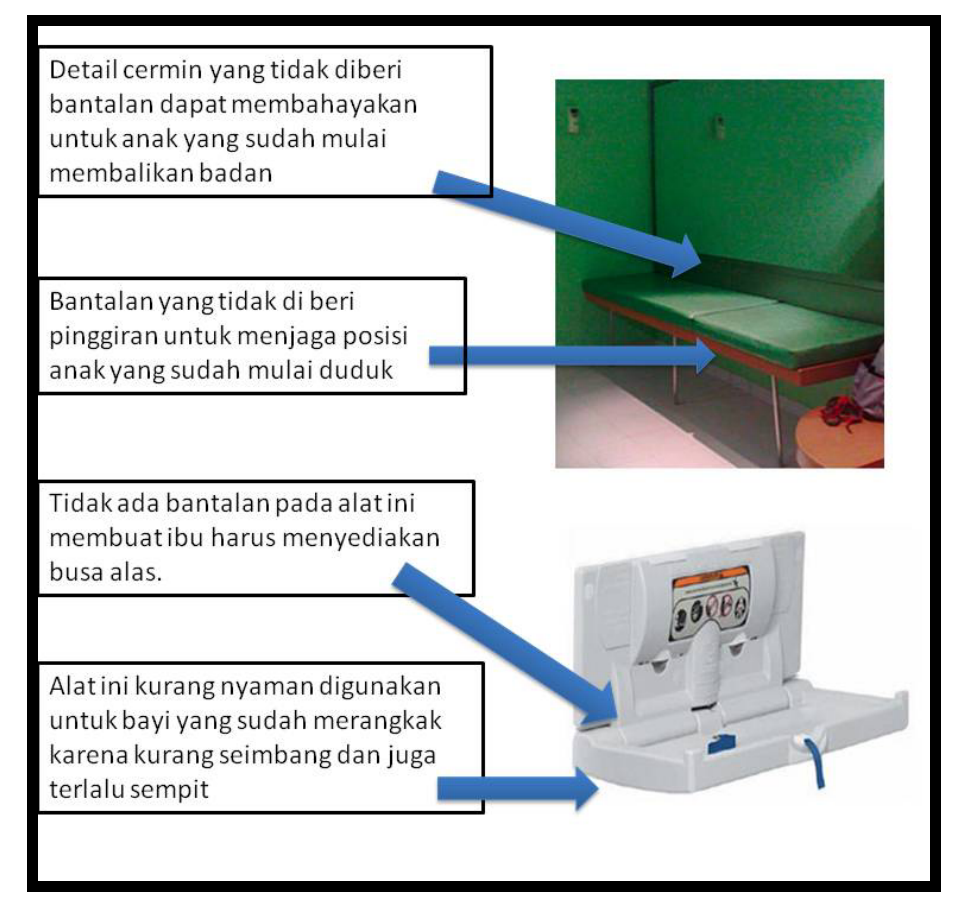

Gambar 10 Pilihan Meja untuk Ganti Popok yang Kurang Nyaman

Pilihlah bahan yang merupakan bahan alami seperti kayu, bahan katun, kulit untuk lapisan sofa serta bentuk yang tumpul atau bantalan pada pinggiran furniturnya. Seperti yang terlihat pada gambar berikut.

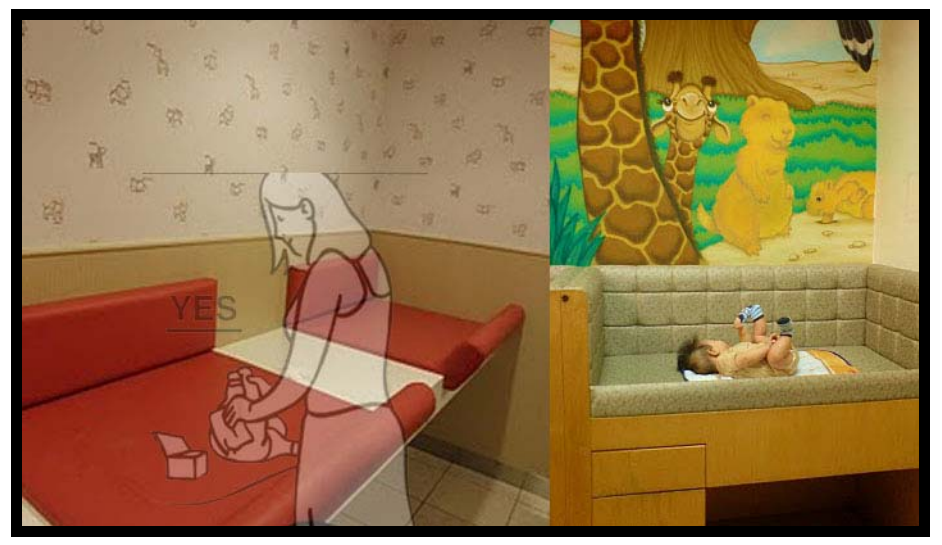

Gambar 11 Pilihan Meja untuk Ganti yang Nyaman dan Aman

Untuk bentuk furnitur sebaiknya menggunakan bentuk sederhana namun lebih dipilih yang fungsional. Bentuk menggunakan tema juga dapat diambil dari gambar binatang, bentuk huruf, angka dan bentuk-bentuk sederhana seperti lingkaran, kotak, persegi panjang, segitiga ataupun bola, alasan pemilihan bentuk-bentuk sederhana dapat menstimulasi si anak untuk mengenal dasar bentuk yang mudah dikenalinnya. Hindari penggunaan bentuk yang terlalu sulit seperti terlalu banyak detail serta bentuk pinggiran yang tajam untuk mengurangi kecelakaan yang dapat terjadi pada pengerjaan detail yang tidak rapih. 


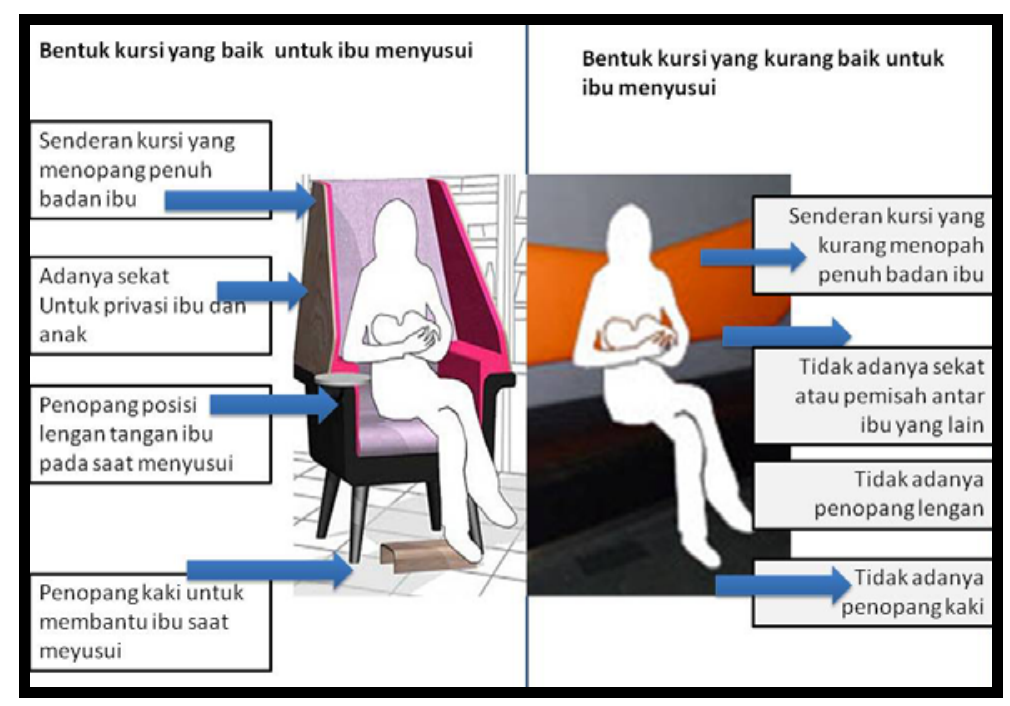

Gambar 12 Pilihan Kursi yang Nyaman dan Tidak Nyaman untuk Menyusui

\section{Pemilihan Warna}

Pengenalan warna untuk usia bayi 0-12 bulan masih hanya membedakan sedikit warna, namun untuk menstimulasi tentang warna pada anak juga dapat digunakan warna selain primer seperti warna sekuder dan warna tersier. Warna yang digunakan pada ruang ibu dan anak dapat dipilih menggunakan komposisi teori warna triad yang lebih mengesankan ceria.
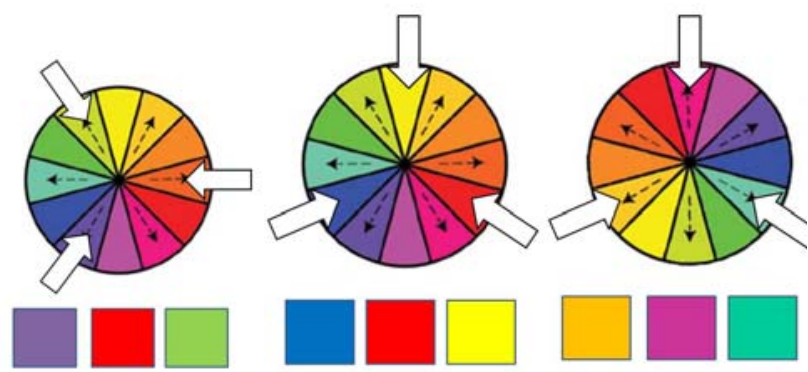

Gambar 13 Komposisi warna triad pada roda warna

Hindari penggunaan warna yang monoton seperti warna dinding dan sofa yang sama karena akan berkesan suram dan tidak menstimulasi kreastifitas si anak seperti Gambar 14.

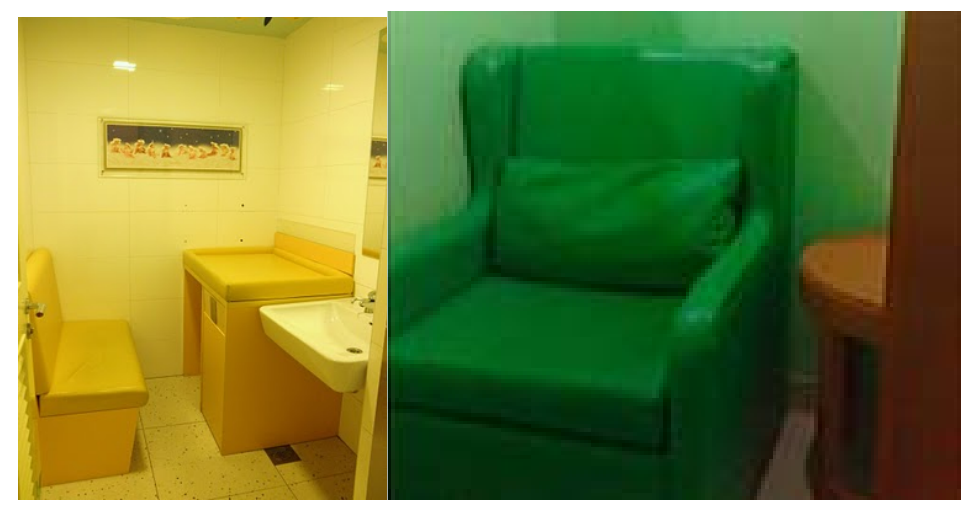

Gambar 14 Area Menyusui dengan Pemakaian Warna yang Monoton 


\section{Akustik dan Penghawaan}

Sisi akustik terkadang adalah bagian yang terlupakan, karena dianggap tidak perlalu penting. namun anggapan ini salah karena ruangan ibu dan anak ini mempunyai beberap teknik yang perlu direncanakan seperti area ruang menyusui yang sebaiknya diberi kedap suara untuk tingkat kebisingan tangisan bayi dan teriakan anak yang juga sedang menggunakan ruangan tersebut. Pemasangan sound system dengan musik yang lembut dapat membantu mood atau perasaan si ibu yang sedang menyusui. Bila pemasangan musik yang terlalu keras dapat membuat si anak merasa tidak nyaman karena refleks bayi yang tertarik dengan bunyi selain suara ibunya.

Untuk sistem penghawaan, ukuran suhu yang nyaman bagi bayi adalah antar $26-27^{\circ} \mathrm{C}$.namun terkadang ada beberapa kebiasaan dari ibu bayi yang membiasakan kamar bayinnya dengan ukuran suhu dibawah $25^{\circ} \mathrm{C}$. Bila mall tersebut menggunakan sistem ac terkontrol, alangkah lebih baik dapat menyediakan kontrol tersendiri pada ruangan ini, agar dapat menyesuaikan suhu sesuai dengan kenyamanan ibu dan anak tersebut. Bila penggunaan AC split maka akan lebih mudah untuk si ibu menyesuaikan suhu udara pada ruangan tersebut.

\section{Pencahayaan}

Untuk pencahayaan pada nursery room dapat digunakan kombinasi tipe pencahayan direct dan indirect lighting untuk area menyusui untuk memberikan kesan lembut dan hangat pada saat ibu menyusui, namun untuk area memberihkan popok lebih baik digunakan direct lampu ataupun jenis watt lampu yang lebih terang sehingga pada saat membersihkan tidak ada satupun yang luput dari pandangan si ibu.

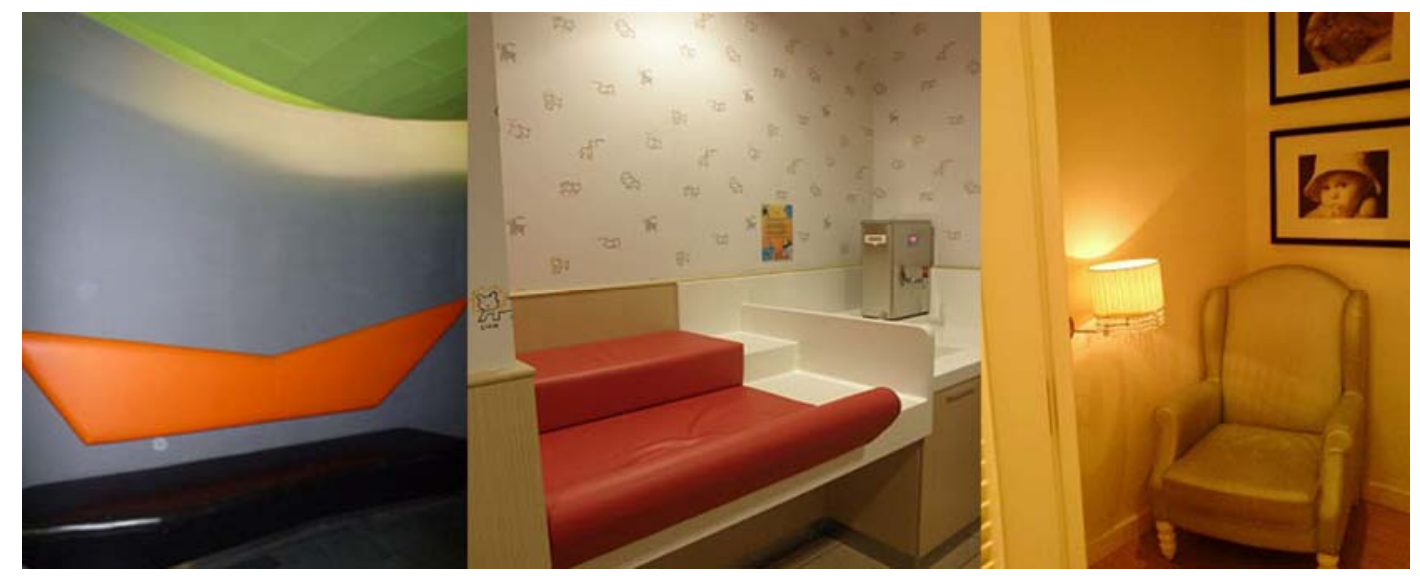

Gambar 15 Jenis Pencahayaan Direct dan Indirect pada Ruang Menyusu

\section{Bilik Menyusui}

Fungsi dari bilik menyusui sangatlah penting bagi kenyamanan si bayi maupun si ibu. Karena pada saat menyusui, konsentrasi si anak perlu dijaga agar tidak terganggu dengan kehadiaran orang lain selain ibunya ataupun terganggu oleh aktifitas orang lain lakukan didalam ruangan tersebut. Bilik ini juga berfungsi untuk menjaga privasi bagi si ibu yang kurang merasa nyaman dengan segala kekurangannya pada saat menyusui bayinya. Berikut adalah contoh dari bilik-bilik menyusui. 


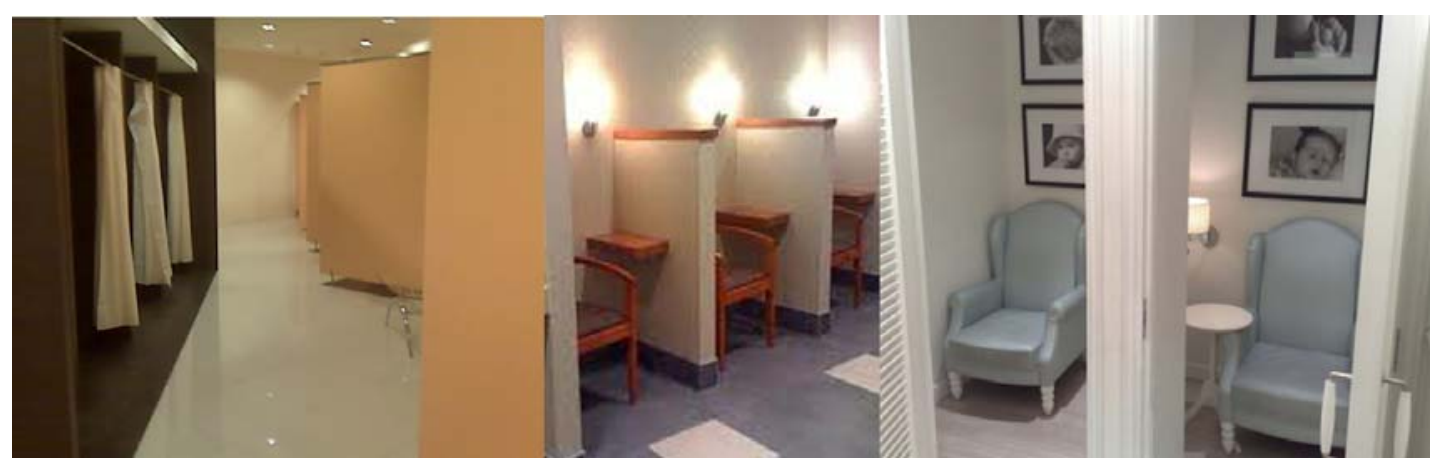

Gambar 16 Bilik-bilik menyusui

Bilik menyusui dapat menggunakan partisi yang terbuat dari gypsum dengan pintu ataupun dengan penutup tirai dengan ukuran tinggi dari atap sampai lantai, namun untuk keterbatasan ruangan dapat juga menggunakan partisi setengah dengan ketinggian hanya untuk membatasi pandangan pada saat posisi menyusui duduk si ibu.

\section{Area Parkir Stroller}

Stroller atau kereta dorong bayi sudah menjadi barang yang pasti dibawa oleh orang tua yang mempunyai balita disetiap aktifitas berbelanja. Stoller ini mempunyai ukuran yang cukup besar, oleh sebab itu parkir stroller menjadi satu solusi untuk menyimpan selagi orang tua melakukan kegiatan ganti popok, menyusui, memberikan makan di restaurant dan juga pergi toilet. Berikut contoh-contoh dari parkir kereta dorong.

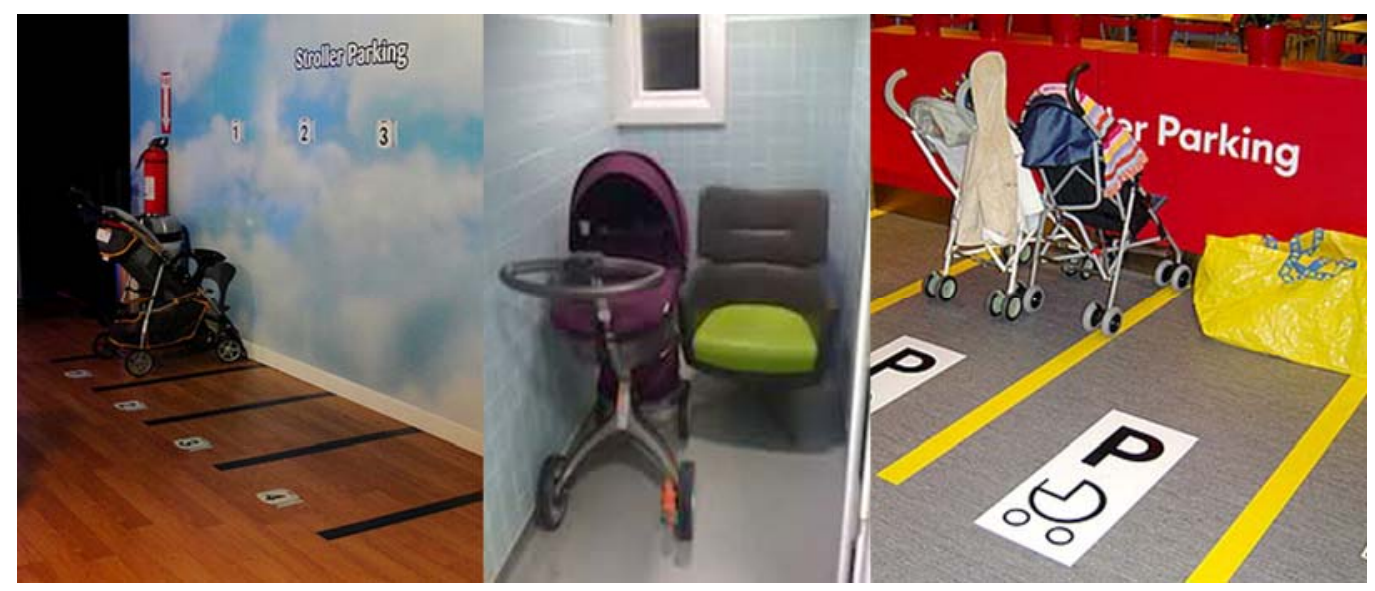

Gambar 17 Area parkir stroller

\section{PENUTUP}

Selain pentingnya keberadaan sebuah ruang ibu dan anak bukan hanya menjadi penunjang suksesnya program menyusui ekslusif namun juga dapat menjadikan sebuah motivasi ibu dengan didukungan kegiatan tersebut oleh banyak kalangan. Sebuah interior ruang ibu dan anak yang didesain dengan mempertimbangkan aspek teknis dan non-teknis akan membangun perasaan atau mood si ibu dalam memberikan asinya untuk anaknnya. 
Hasil dari penjabaran dari bagian pembahasan di jurnal ini dapat menjadi landasan untuk mengembangkan penilitian dengan data kuantitatif yang dapat dilakukan dengan survey kepuasan mengenai fasilitas yang disediakan terhadap ibu-ibu pengguna ruang menyusui di area public. Aplikasi lebih jauh dapat menjadi acuan bagi perkantoran, management mall dan public area lainnya untuk meningkatkan kepuasan pelanggan dengan memberikan services excellent pada kelengkapan fasilitas ruang ibu dan anak. Selain itu penelitian ini dapat berlanjut, apakah dampak luas dari dukungan gerakan perusahaan sayang bayi dapat menambah tingkat pengunjung di pusat perbelanjaan ataupun kinerja baik dari karyawatinya yang disediakan tempat fasilitas sayang bayi seperti tempat penitipan anak dan ruang memerah ASI.

\section{DAFTAR PUSTAKA}

Ardhiati, Y., Tari, G., Kalla, T. A., \& Pratiwi, O. (2007). Tema, cinta dan gaya: Day care, preschool and boutique: Fasilitas bagi kanak-kanak dan balita di lingkungan Apartemen di Jakarta. Dimensi Seni Rupa dan Desain: 37.

Jamris, M. (2006). Perkembangan dan pengembangan anak usia Taman Kanak-Kanak. Jakarta: Grasindo.

Sentra Laktasi Indonesia. (2009, 1 April). Selasi. Diakses pada 3 Januari 2011, dari http://selasi.net/artikel/perusahaan-sayang-ibu/55-keuntungan-untuk-perusahaan.html

UNICEF. (2010, 9 Agustus). UNICEF Indonesia. Diakses pada 3 Januari 2011, dari http://www.unicef.org/indonesia/id/media_13921.html 